\title{
Transcription factor MITF regulates cardiac growth and hypertrophy
}

\author{
Sagi Tshori, ${ }^{1}$ Dan Gilon, ${ }^{2}$ Ronen Beeri, ${ }^{2}$ Hovav Nechushtan, ${ }^{3}$ \\ Dmitry Kaluzhny, ${ }^{1}$ Eli Pikarsky, ${ }^{4}$ and Ehud Razin ${ }^{1}$
}

\author{
${ }^{1}$ Department of Biochemistry, Hebrew University Medical School, Jerusalem, Israel. ${ }^{2}$ Heart Institute, ${ }^{3}$ Department of Oncology, and \\ ${ }^{4}$ Department of Pathology, Hadassah Hebrew University Medical Center, Jerusalem, Israel.
}

\begin{abstract}
High levels of microphthalmia transcription factor (MITF) expression have been described in several cell types, including melanocytes, mast cells, and osteoclasts. MITF plays a pivotal role in the regulation of specific genes in these cells. Although its $\mathrm{mRNA}$ has been found to be present in relatively high levels in the heart, its cardiac role has never been explored. Here we show that a specific heart isoform of MITF is expressed in cardiomyocytes and can be induced by $\beta$-adrenergic stimulation but not by paired box gene 3 (PAX3), the regulator of the melanocyte MITF isoform. In 2 mouse strains with different MITF mutations, heart weight/body weight ratio was decreased as was the hypertrophic response to $\beta$-adrenergic stimulation. These mice also demonstrated a tendency to sudden death following $\beta$-adrenergic stimulation. Most impressively, 15-month-old MITF-mutated mice had greatly decreased heart weight/body weight ratio, systolic function, and cardiac output. In contrast with normal mice, in the MITF-mutated mice, $\beta$-adrenergic stimulation failed to induce B-type natriuretic peptide (BNP), an important modulator of cardiac hypertrophy, while atrial natriuretic peptide levels and phosphorylated Akt were increased, suggesting a cardiac stress response. In addition, cardiomyocytes cultured with siRNA against MITF showed a substantial decrease in BNP promoter activity. Thus, for what we believe is the first time, we have demonstrated that MITF plays an essential role in $\beta$-adrenergic-induced cardiac hypertrophy.
\end{abstract}

\section{Introduction}

Cardiomyocytes are terminally differentiated and lose their ability to proliferate soon after birth. The adult myocardium responds to a variety of pathologic stimuli by hypertrophic growth that frequently progresses to heart failure, arrhythmias, and sudden death. At the cellular level, cardiac hypertrophy is characterized by an increase in cell size and reactivation of the fetal gene program (1), including cardiac hypertrophy markers such as the natriuretic peptides, atrial natriuretic peptide (ANP) and B-type natriuretic peptide (BNP). Defined transcription factors are involved in this process. These include cardiac transcription factors such as GATA4, MEF2, and immediate early genes, such as c-jun and c-fos $(2,3)$. The cellular mechanisms underlying the transition from compensatory to deleterious hypertrophy remain to be elucidated; however, both the MAPK pathway and Wnt signaling, which are important in the regulation of cardiac hypertrophy (3), are known to upregulate and activate microphthalmia transcription factor (MITF) by phosphorylation (4-6).

MITF is a basic helix-loop-helix leucine zipper (bHLH-Zip) DNAbinding protein (7). Its gene resides at the $m i$ locus in mice (8), and mutations of this gene (9) result in deafness, bone loss in dominantnegative $\mathrm{mi} / \mathrm{mi}$ mice, small eyes, and poorly pigmented eyes and skin. In humans, heterozygous mutation in this gene causes Waardenburg syndrome type II (10), resulting in hypopigmentation and deafness. In the current work, we have used 2 different MITF-mutated mouse

Nonstandard abbreviations used: ANP, atrial natriuretic peptide; bHLH-Zip, basic HLH leucine zipper; BNP, b-type natriuretic peptide; BW, body weight(s); $\mathrm{CO}$, cardiac output; HLH, helix-loop-helix; HR, heart rate; HW, heart weight(s); LVEDD, LV end diastolic diameter; LVESD, LV end systolic diameter; MITF, microphthalmia transcription factor; $\mathrm{p}$, phosphorylated; Pax3, paired box gene 3; SF, shortening fraction; TFE, transcription factor $\mathrm{E}$.

Conflict of interest: The authors have declared that no conflict of interest exists. Citation for this article: J. Clin. Invest. 116:2673-2681 (2006). doi:10.1172/JCI27643. strains. Mice with the ce/ce mutation lack the Zip domain of MITF because of a stop codon between the HLH and Zip domains while their normal littermates $(s p / s p)$ express the full-length protein, except for exon $6 \mathrm{a}$ (11) (Figure 1, A and B). The truncated protein is unable to dimerize or to bind DNA (12). Mice carrying the $t g / t g$ mutation have an insertion of approximately 50 copies of a transgene integrated inside the MITF promoter, and it seems that they are unable to express MITF (13) (Figure 1B). MITF regulates the transcription of a variety of cell-specific genes, such as tyrosinase and pink-eyed Pmel 17 (silver) (14), c-kit (15), granzyme B (16) and tryptophan hydroxylase, and mast cell proteases, such as mouse mast cell protease 6 (mMCP6) (17).

Several alternate MITF splice products have been described, including a number of alternatively spliced $5^{\prime}$ exons. While exon $1 \mathrm{~m}$ is melanocyte specific, other exons (such as $1 \mathrm{a}$ and $1 \mathrm{~h}$ ) are more widely expressed. These exons are widely spaced in the genomic DNA and are expressed from different promoters ( $\mathrm{M}, \mathrm{A}$, and $\mathrm{H})$.

The activity of MITF as a transcription factor is influenced in a complex manner by different intracellular proteins. For example, in vitro studies have indicated that MITF can form heterodimers with the 4 related MITF/transcription factor E (MITF/TFE) family members, TFEB, TFEC, TFE3, and upstream stimulatory factor 2 (USF2) $(12,18)$. MITF can also form heterodimers with c-jun and c-fos through its Zip domain (19). We have recently identified 2 inhibitors of MITF transcriptional activity, Hint (20) and PIAS3 (21).

Although MITF has been shown to be transcribed in high levels in the heart (7), its physiological role in cardiac function has never been explored. Here we show that MITF is highly expressed in cardiac myocytes. Moreover, MITF-mutated mice show a diminished hypertrophic response to $\beta$-adrenergic stimulation, decreased cardiac function, and a tendency to sudden death. Middle-aged MITF-mutated mice have a much smaller heart mass and have greatly decreased cardiac function and cardiac output (CO). 

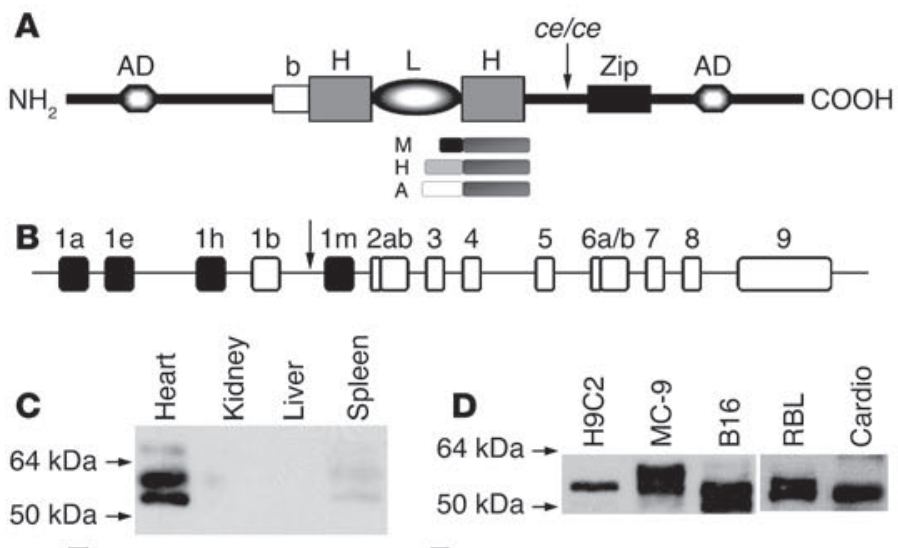

E

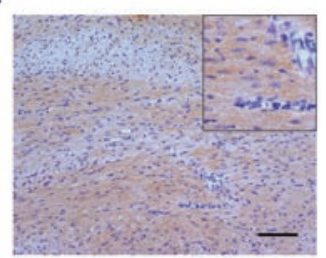

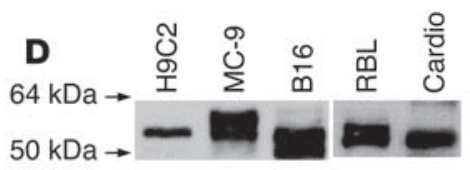

$\mathbf{F}$

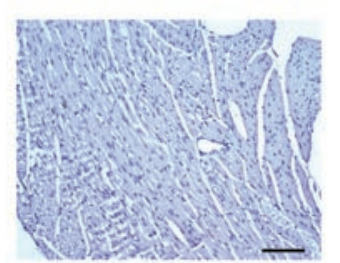

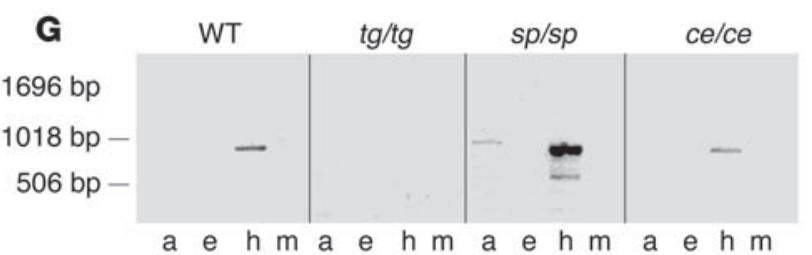

H

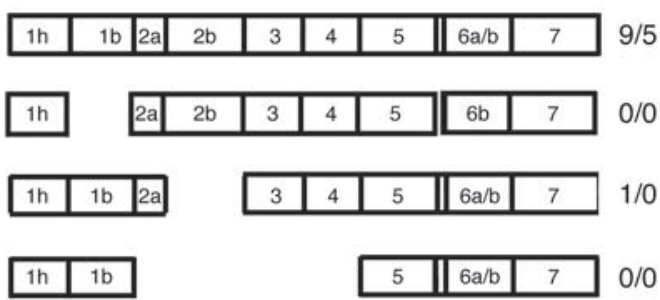

Figure 1

MITF is expressed in cardiomyocytes. (A) Structure of MITF protein. The ce/ce mutation is a stop codon between the bHLH and the leucine zipper. b, basic domain; zip, leucine zipper. Also shown is a schematic representation of MITF protein products, with different $\mathrm{N}$ termini and common C terminus. (B) Genomic organization of the mi locus. $\mathrm{tg} / \mathrm{tg}$ mice have an insertion of about 50 copies of a transgene incorporated into the promoter region of MITF. Filled boxes represent alternative promoters. Arrow indicates $\mathrm{tg} / \mathrm{tg}$ insertion site. (C) Western blot analysis of heart, liver, kidney and spleen of normal mice. Strong expression of MITF is noted in the heart. (D) Western blot analysis of H9C2 cardiomyocytes, MC-9 mast cells, B16 melanoma cells, rat basophilic leukemia (RBL) cells, and primary culture of rat neonatal cardiomyocytes (cardio). MITF appears in cardiomyocytes at approximately the same molecular weight as in mast cells but not in melanocytes. (E and F) Immunohistochemical staining of MITF using monoclonal antibody directed against the $\mathrm{NH}_{2}$ terminus in normal $(\mathbf{E})$ and $\operatorname{tg} / \mathrm{tg}$ mutated (F) hearts. MITF staining is absent in $\mathrm{tg} / \mathrm{tg}$ mutated hearts. Scale bars: $100 \mu \mathrm{m}$. Higher magnification appears in the inset. (G) cDNA from hearts of either WT or tg/tg and ce/ce MITF-mutated mice and their normal littermates $(s p / s p)$ were amplified by PCR. Four mouse MITF alternative first exons $(1 \mathrm{a}, 1 \mathrm{e}, 1 \mathrm{~h}$, and $1 \mathrm{~m})$ were used as sense primers, and exon 5 was used as antisense. Numbers on the left indicate molecular weight (bp). (H) Schematic representation of splicing patterns described for MITF. Numbers on the left of slashes represent clones including exon 6a; numbers on the right represent clones without exon 6a. Most clones are full length, including exon 6a.

Whereas in normal littermates, the BNP level is greatly increased in response to $\beta$-adrenergic stimulation, in MITFmutated mice, this response is almost abolished. These data imply that cardiac hypertrophy is impaired in MITF-mutated mice, demonstrating that MITF plays an important role in this physiological response.

\section{Results}

MITF expression in the heart. MITF expression was detected in cardiac myocytes using PCR analysis, Western blot analysis, and immunohistochemical staining. Protein lysates were extracted from heart, kidney, liver, and spleen of WT C57BL/6 mice. A high level of MITF expression was detected in the heart compared with the other tissues (Figure 1C). There are several known isoforms of MITF, differing at the $\mathrm{NH}_{2}$ terminus (Figure 1, A and B). A short form (MITF M) is expressed in melanocytes while the longer isoforms are expressed in other cells, including osteoclasts and mast cells (22). MITF was expressed in cardiomyocytes both in the $\mathrm{H} 9 \mathrm{C} 2$ cell line and in rat neonatal primary culture and was detected at the approximate molecular weight of mast cell MITF (Figure 1D). An upper band appears in some of the lanes, probably due to phosphorylation of MITF (4). Immunohistochemical staining against MITF demonstrated the expression of MITF in cardiomyocytes in normal hearts (Figure 1E) whereas no expression was detected in $\mathrm{tg} / \mathrm{tg}$ mutated mouse hearts (Figure $1 \mathrm{~F}$ ).

Several alternative splicing products of MITF have been described, including splicing of the first exon. The MITF gene contains different promoters whose activation is probably dependent on the tissue or cell type. The regulation of MITF expression has only been studied in depth in melanocytes, so little is known about the regulation of its expression in other cells.

At least 4 alternate MITF first exons have been described so far in mice (Figure 1B). In order to characterize MITF subtypes in the heart and to verify the lack of MITF expression in $\mathrm{tg} / \mathrm{tg}$ mice, PCR was performed on cDNA from $\mathrm{tg} / \mathrm{tg}$ and $\mathrm{ce} / \mathrm{ce}$ MITF-mutated mice and their normal littermates (Figure $1 \mathrm{G}$ ). The primary transcript identified was from exon $1 \mathrm{~h}$ in normal and in ce/ce mutated mice. No transcript was detected for $\mathrm{tg} / \mathrm{tg}$ mutated mice, supporting the initial report (7).

RNA RT-PCR amplification, cloning, and sequencing of MITF cDNAs identified several MITF splice products in cardiomyocytes (Figure 1H). Exon 6a, an 18-bp alternate exon, was present in approximately two-thirds of MITF splice products. Exon $6 a$ helps stabilize the MITF-DNA interaction, but its physiological role is unknown. While various short isoforms of MITF, whose biochemical function is unknown, are described in the literature, almost all transcripts were full length. 


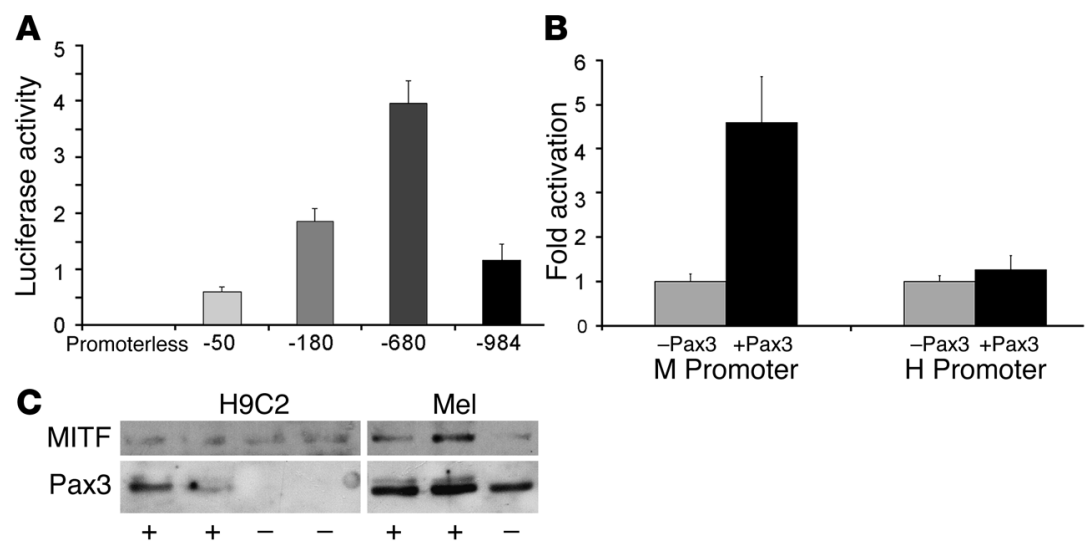

Figure 2

Characterization of MITF promoter in cardiomyocytes. (A) Luciferase reporters under the control of various fragments of MITF $\mathrm{H}$ promoter were transfected into $\mathrm{H} 9 \mathrm{C} 2$ cardiomyocytes. Designations of the promoter fragments are relative to the transcription start site. The luciferase activity was normalized using total protein concentrations. Results represent mean \pm SEM of 1 representative experiment out of 3 . (B) Luciferase reporter under the control of either MITF M or MITF H promoter was cotransfected with Pax3 expression vector into NIH 3T3 cells. Pax3 overexpression activated the MITF M promoter but not the MITF H promoter. Results were normalized as described above, and fold activation values were calculated. (C) Pax3 expression vector was transfected into melanocytes (mel) and H9C2 cells. Expression of Pax3 and MITF was assessed by Western blot analysis. Pax3 overexpression resulted in raised MITF levels in melanocytes alone. One representative experiment out of 3 is shown.

Characterization of MITF promoter in cardiomyocytes. Several plasmids containing the sequence upstream of the MITF transcription start site in the heart were constructed by genomic PCR amplification and subsequent ligation into the pSP72 luciferase-reporter vector. These constructs were transfected into H9C2 cardiomyocytes in order to determine the promoter elements that are responsible for MITF transcription in the heart.

Expression of MITF was elevated by increasing the length of the upstream sequence up to -680 (Figure 2A). Introduction of the longest construct (-984) gave a lower level of transcriptional response as compared with the -680 construct. This could be explained by the presence of unknown suppressor elements in the promoter upstream of -680 . Paired box gene 3 ( $\mathrm{Pax} 3$ ) has been shown to induce MITF

\section{Figure 3}

Attenuated cardiac hypertrophy in mice receiving isoproterenol. (A) Western blot analysis of $\mathrm{H} 9 \mathrm{C} 2$ cells activated for 6 hours with isoproterenol (iso) or saline (con). In the upper blot, anti-MITF antibody and in the lower blot, anti- $\beta$-actin antibody were used. Isoproterenol induced MITF expression. (B) Either MITF H or M promoter constructs were transfected into $\mathrm{H} 9 \mathrm{C} 2$ cardiomyocytes. Forty-eight hours after transfection, either saline or 2.5 or $10 \mu \mathrm{M}$ isoproterenol were added to the medium for 6 hours. Results were normalized as described above and fold activation values relative to saline-treated cells (control) were calculated. Results represent the mean of 3 independent experiments. Isoproterenol induced promoter activity of MITF H but not MITF M. (C) Hearts of 1 representative mouse for each group. Mice were administered either saline or isoproterenol for 7 days. (D and $\mathbf{E}) \mathrm{HW} / \mathrm{BW}$ ratios of $s p / s p$ and ce/ce mice (D) ( $n=12$ per group) and WT and tg/tg mice (E) ( $n=6$ per group) receiving either saline or isoproterenol for 7 days. Results represent mean \pm SEM. (F) Myocyte diameter of $s p / s p$ and ce/ce mice receiving either saline or isoproterenol for 7 days. Results represent mean \pm SEM.

transcription from the $\mathrm{M}$ promoter in melanocytes. In order to determine whether Pax3 could induce MITF transcription from the $\mathrm{H}$ promoter in cardiomyocytes, Pax3 was cotransfected with either the MITF M promoter construct or the MITF H promoter construct into NIH 3 T3 cells. Pax3 activated the $M$ promoter approximately 5-fold as compared with $M$ promoter transcriptional activity in the absence of Pax3 (Figure 2B). However, Pax3 was unable to activate the MITF $\mathrm{H}$ promoter construct. Overexpression of Pax 3 in melanocytes resulted in increased MITF expression (Figure 2C). However, Pax3 overexpression in $\mathrm{H} 9 \mathrm{C} 2$ cells did not affect MITF expression.

H9C2 cardiomyocytes were transfected with either the $\mathrm{H}$ promoter construct or the M promoter construct, followed by isoproterenol activation. Upon activation, MITF $\mathrm{H}$ promoter activity was induced (Figure 3A). However, MITF $\mathrm{M}$ promoter activity was not induced even with a high dose of isoproterenol. H9C2 cells were cultured with medium containing $10 \mu \mathrm{M}$ isoproterenol for 6 hours, and MITF protein level was determined by Western blot analysis. MITF level was significantly induced by isoproterenol (Figure 3B). Thus, our results show that the regulation of MITF in cardiomyocytes is different from that in melanocytes.

Characterization of the heart of MITF-mutated mice. Heart weights (HW) and body weights (BW) of 5-week-old normal and MITFmutated mice were determined, and the HW/BW ratios were calculated (Table 1). The HW/BW ratios of $\mathrm{tg} / \mathrm{tg}$ mice were decreased by $12 \%$ compared with their normal littermates $(P<0.005, n=6)$, and $\mathrm{HW} / \mathrm{BW}$ ratios of $c e / c e$ mice were decreased by $8 \%$ compared with their normal littermates $(P<0.05, n=12)$. No significant differences in BW were observed in either MITF-mutated mice model

A

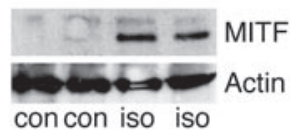

C

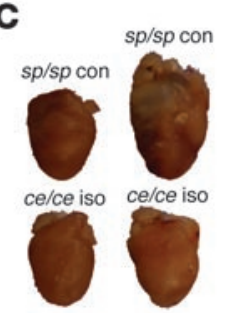

E

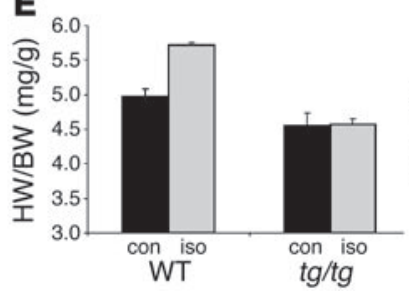

D
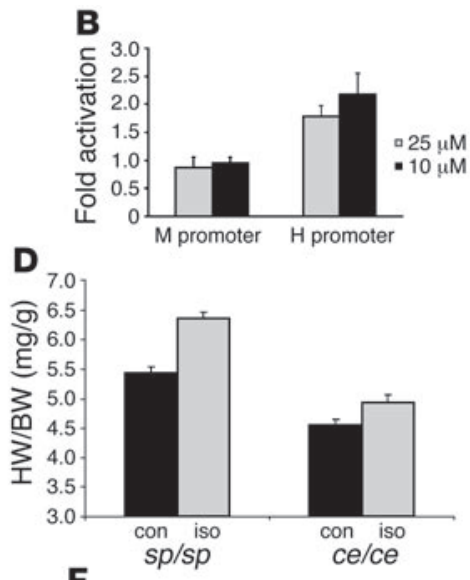

$\mathbf{F}$

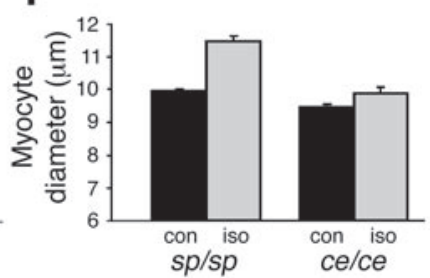




\section{Table 1}

BW and HW/BW ratios of MITF-mutated mice and their normal littermates

$\begin{array}{lccc} & \text { BW }(\mathbf{g}) & \text { HW }(\mathbf{m g}) & \text { HW/BW }(\mathbf{m g} / \mathbf{g}) \\ s p / s p(n=12) & 19.80 \pm 0.64 & 92.2 \pm 3.4 & 4.64 \pm 0.11 \\ c e / c e(n=12) & 18.40 \pm 0.80 & 77.8 \pm 4.1^{\mathrm{A}} & 4.29 \pm 0.08 \mathrm{~B} \\ \text { WT }(n=6) & 19.60 \pm 0.41 & 106.2 \pm 6.6 & 5.46 \pm 0.13 \\ \operatorname{tg} / \operatorname{tg}(n=6) & 18.80 \pm 0.86 & 88.0 \pm 5.4^{\mathrm{B}} & 4.77 \pm 0.11^{\mathrm{A}}\end{array}$

BW and HW of 5-week-old MITF-mutated mice (tg/tg and ce/ce) and their normal littermates (WT and $s p / s p$, respectively) were measured. Results are expressed as mean \pm SEM. ${ }^{A} P<0.01 ;{ }^{B} P<0.05$ compared with normal littermates.

(Table 1). Histological staining did not reveal any gross pathology in either $c e / c e$ or $\mathrm{tg} / \mathrm{tg}$ MITF-mutated mice.

Isoproterenol-induced cardiac bypertrophy is abnormal in MITF-mutated mice. In order to further explore the importance of MITF in the heart, we used isoproterenol administration as a cardiac hypertrophy model. Six-week-old ce/ce MITF-mutated mice and their normal littermates $(s p / s p)$ were administered either saline or isoproterenol for 7 days. Isoproterenol induced an approximately $19 \%$ increase of $\mathrm{HW} / \mathrm{BW}$ ratio in normal mice (Figure 3D), but only a $7 \%$ increase was observed in ce/ce mutated mice $(P<0.00001, n=12)$. Three of the $\mathrm{ce} / \mathrm{ce}$ mice that received isoproterenol suffered sudden death immediately after isoproterenol administration, suggesting an arrhythmogenic cause for sudden death. None of the other mice died, and none of the deaths occurred before the fifth day of treatment.

Normal and $\mathrm{tg} / \mathrm{tg}$ MITF-mutated mice were administered either saline or isoproterenol for 7 days (Figure 3E). In normal littermates, $\mathrm{HW} / \mathrm{BW}$ ratio was increased by approximately $13 \%(P<0.01, n=6)$, while in $t g / t g$ MITF-mutated mice no significant increase was observed. Myocyte cell diameter was measured by microscopic analysis of fixed sections of LVs. Isoproterenol caused an increase of $15 \%$ in myocyte cell diameter in normal littermates (Figure $3 \mathrm{~F}$ ) whereas in ce/ce mice, there was only a $4 \%$ increase $(P<0.00001, n=4)$.

We attempted an aortic banding model in MITF-mutated mice. In both WT and MITF-mutated mice, all sham-operated mice survived. Nine out of 13 WT mice survived aortic banding. However, only 4 out of 10 MITF-mutated mice survived aortic banding. Since most deaths occurred within 24 hours after surgery, one could postulate a cardiac cause of death, but we have no data to support this theory.

Cardiac function of MITF-mutated mice. The physiological effect of MITF was studied by echocardiography on ce/ce mice and their normal littermates who had received either saline or isoproterenol for 7 days. LV end diastolic diameter (LVEDD) was not significantly increased in isoproterenol-treated ce/ce mice. However, LV end systolic diameter (LVESD) was significantly increased in isoproterenol-treated $\mathrm{ce} / \mathrm{ce}$ mice compared with all groups $(P<0.05, n=8)$ (Table 2). Shortening fraction (SF) was not affected by isoproterenol administration in normal littermates $(60.8 \% \pm 4.0 \%$ versus $60.7 \% \pm 4.5 \%$ ). However, SF was reduced to $45.4 \%$ in

\section{Table 2} enol or normal saline ce/ce mice receiving isoproterenol $(P<0.01)$ (Table 2$)$. The $t g / \operatorname{tg}$ MITFmutated mice had decreased cardiac function compared with their normal littermates (Table 3), as evident by the decrease in SF $(62.6 \%$ versus $44.6 \%, P<0.001, n=6)$. However, no decrease of cardiac function in response to isoproterenol administration was observed.

Function of the $\beta$-adrenergic system was evaluated by measuring peak heart rate (HR) and cAMP levels immediately following either isoproterenol or normal saline administration. Peak HR was similarly elevated in normal and MITF-mutated mice (from $446 \pm 21$ to $500 \pm 14$ and from $456 \pm 22$ to $516 \pm 14 \mathrm{bpm}, n=5)$. cAMP levels were also similarly increased from $665 \pm 56 \mathrm{pg} / \mu \mathrm{l}$ to $981 \pm 85 \mathrm{pg} / \mu \mathrm{l}$ and from $684 \pm 38 \mathrm{pg} / \mu \mathrm{l}$ to $966 \pm 77 \mathrm{pg} / \mu \mathrm{l}$, respectively. These results indicate that the $\beta$-adrenergic system is not impaired in MITF-mutated mice.

Characterization of the hearts of middle-aged MITF-mutated mice. Morphometric and echocardiographic measurements were performed on 15-month-old normal ( $s p / s p)$ and MITF-mutated (ce/ce) mice. No significant difference in BW was noted (Table 4) while tibial length was only slightly decreased in MITF-mutated mice. HW and chamber weights were decreased by approximately 30\% in MITFmutated mice. This decrease was more accentuated in the RV than in the $\mathrm{LV}$ (55\% versus 19\% respectively). Results were highly significant when corrected both to BW and to tibial length. It should be noted that HW/BW ratio was increased in 15-month-old normal mice compared with 5 -week-old mice $(5.44 \pm 0.18$ versus $4.64 \pm 0.11)$ but not in MITF-mutated mice (4.29 \pm 0.08 versus $4.22 \pm 0.21$ ).

While diastolic diameters were not significantly different between normal and MITF-mutated mice (Table 5), LVESD was increased in MITF-mutated mice. SF was reduced from $43.9 \%$ in normal mice to $32.8 \%$ in MITF-mutated mice (Table 5 and Figure 4). Cardiacindexwas also decreased from $2.43 \mathrm{ml} / \mathrm{min} / \mathrm{g}$ to $1.46 \mathrm{ml} / \mathrm{min} / \mathrm{g}$. Middle-aged MITF-mutated mice showed decreased cardiac mass, decreased cardiac function, and lower CO.

BNP expression in normal and MITF-mutated mice. BNP is both a marker and a modulator of cardiac hypertrophy. Thus, BNP mRNA level was measured by real-time PCR in normal and MITF-mutated mice treated with either saline or isoproterenol. BNP levels in WT mice were increased 5- to 8-fold after isoproterenol administration (Figure 5A). Interestingly, in ce/ce MITFmutated mice, BNP mRNA was not increased $(P<0.005, n=6)$. There was no significant difference between saline- and isoproterenol-treated ce/ce mutated mice. Similarly, BNP mRNA levels

Echocardiography of normal $(s p / s p)$ and MITF-mutated mice $(c e / c e)$ receiving either isoproter-

$\begin{array}{lcccc} & \begin{array}{c}\boldsymbol{s p} / \boldsymbol{s p} \text { saline } \\ (\boldsymbol{n}=\mathbf{8})\end{array} & \begin{array}{c}\boldsymbol{s p} / \boldsymbol{s p} \text { iso } \\ (\boldsymbol{n}=\mathbf{8})\end{array} & \begin{array}{c}\boldsymbol{c e} / \boldsymbol{c e} \text { saline } \\ (\boldsymbol{n}=\mathbf{8})\end{array} & \begin{array}{c}\boldsymbol{c e} / \boldsymbol{c e} \text { iso } \\ (\boldsymbol{n}=\mathbf{8})\end{array} \\ & 3.05 \pm 0.26 & 3.07 \pm 0.17 & 2.94 \pm 0.18 & 3.31 \pm 0.17 \\ \operatorname{LVEDD}(\mathrm{mm}) & 1.23 \pm 0.20^{\mathrm{A}} & 1.16 \pm 0.09^{\mathrm{A}} & 1.33 \pm 0.09^{\mathrm{A}} & 1.69 \pm 0.14 \\ \operatorname{LVESD}(\mathrm{mm}) & 0.52 \pm 0.03 & 0.51 \pm 0.05 & 0.54 \pm 0.04 & 0.47 \pm 0.03 \\ \text { IVSd }(\mathrm{mm}) & 0.58 \pm 0.05 & 0.56 \pm 0.02 & 0.56 \pm 0.05 & 0.50 \pm 0.04 \\ \text { LPWd (mm) } & 60.8 \pm 4.0^{\mathrm{B}} & 60.7 \pm 4.5^{\mathrm{B}} & 54.9 \pm 3.0^{\mathrm{A}} & 45.4 \pm 4.6 \\ \text { SF }(\%) & 497 \pm 27 & 521 \pm 41 & 535 \pm 35 & 523 \pm 36 \\ \text { HR (bpm) } & & & \end{array}$

Normal littermates (sp/sp) and ce/ce MITF-mutated mice were treated for 7 days with either saline or isoproterenol (iso), and cardiac function was measured by echocardiography. IVSd, interventricular septum diastolic diameter; LPWd, left posterior wall diameter. Results are expressed as mean \pm SEM. ${ }_{A}^{A} P<0.05 ;{ }^{B} P<0.01$ compared with isoproterenol-treated ce/ce mice. Isoproterenol administration resulted in significant reduction of SF in ce/ce mice. 


\section{Table 3}

Echocardiography of normal (WT) and MITF-mutated mice (tg/tg) receiving either isoproterenol or normal saline

\begin{tabular}{lcccc} 
& $\begin{array}{c}\text { WT saline } \\
(\boldsymbol{n}=\mathbf{6})\end{array}$ & $\begin{array}{c}\text { WT iso } \\
(\boldsymbol{n}=\mathbf{6})\end{array}$ & $\begin{array}{c}\text { tg/tg saline } \\
(\boldsymbol{n}=\mathbf{6})\end{array}$ & $\begin{array}{c}\text { tg/tg iso } \\
(\boldsymbol{n}=\mathbf{6})\end{array}$ \\
LVEDD (mm) & $2.98 \pm 0.17$ & $3.07 \pm 0.17$ & $3.17 \pm 0.07$ & $3.29 \pm 0.17$ \\
LVESD (mm) & $1.08 \pm 0.17^{\mathrm{A}}$ & $1.16 \pm 0.09 \mathrm{~A}$ & $1.76 \pm 0.15$ & $1.83 \pm 0.19$ \\
IVSd (mm) & $0.47 \pm 0.00$ & $0.51 \pm 0.05$ & $0.47 \pm 0.03$ & $0.46 \pm 0.01$ \\
LPWd (mm) & $0.44 \pm 0.03$ & $0.56 \pm 0.02$ & $0.42 \pm 0.03$ & $0.41 \pm 0.08$ \\
SF (\%) & $62.6 \pm 2.9 \mathrm{~B}$ & $60.7 \pm 4.5^{\mathrm{B}}$ & $44.6 \pm 3.9$ & $45.4 \pm 3.2$ \\
HR (bpm) & $495 \pm 16$ & $521 \pm 41$ & $418 \pm 39$ & $487 \pm 14$ \\
\hline
\end{tabular}

Normal littermates $(s p / s p)$ and ce/ce MITF-mutated mice were treated for 7 days with either saline or isoproterenol, and cardiac function was measured by echocardiography. Results are expressed as mean \pm SEM. ${ }^{A} P<0.05 ;{ }^{B} P<0.01$ compared with isoproterenol-treated ce/ce mice. SF was significantly reduced in $\mathrm{tg} / \mathrm{tg}$ mutated mice. However, isoproterenol administration did not result in further reduction of SF.

did not increase in $\operatorname{tg} / \operatorname{tg}$ MITF-mutated mice (Figure 5B) while a 2 -fold induction was noted in their normal littermates $(P<0.05$, $n=5)$. Thus, MITF-mutated mice have a greatly diminished $\mathrm{BNP}$ response to isoproterenol administration.

The effect of MITF on BNP expression was studied. H9C2 cells were transduced with lentiviral vector expressing either scrambled or MITF-specific siRNA, and 24 hours later, the cells were transfected with BNP promoter-reporter vector. BNP promoter activity was decreased by approximately $40 \%$ by MITF-specific siRNA (Figure 5C). Moreover, while MITF overexpression increased BNP promoter activity, overexpression of the ce/ce mutant form did not increase BNP promoter activity (Figure 5D). Thus, we conclude that the BNP promoter is at least partially regulated by MITF. In contrast with BNP, and as opposed to in normal mice, the induction of ANP by isoproterenol was significantly increased in MITFmutated mice as measured by real-time PCR $(P<0.01, n=8)$ (Figure 5E). In addition, as expected, phosphorylated ERK (p-ERK) was present at low levels in the control mice (Figure $5 \mathrm{~F}$ ). Isoproterenol induced p-ERK 3 -fold in normal mice $(P<0.05, n=5)$ as opposed to the MITF-mutated mice, in which no such induction occurred. Levels of $\mathrm{p}$-Akt were decreased by isoproterenol in normal mice, in contrast with MITF-mutated mice, where the levels were significantly increased $(P<0.01, n=5)$ (Figure 5F).

Neonatal rat cardiomyocytes were transduced with a lentiviral vector expressing either scrambled RNA or siRNA directed against MITF. p-ERK levels were decreased in comparison with those measured following transduction with scrambled control virus (Figure $5 \mathrm{G}$ ). In addition, p-ERK levels were increased in H9C2 cells overexpressing MITF (Figure 5G) while MITF overexpression had no effect on ERK levels. Both ERK1 and ERK2 were similarly phosphorylated by MITF overexpression (Figure 5H). Thus, we conclude that MITF is involved in the phosphorylation of ERK rather than in its expression.

\section{Discussion}

In the present work, we confirmed that MITF is found in the heart and demonstrated that it is expressed in cardiomyocytes where it plays a key regulatory role in cardiac hypertrophy. By using mice carrying mutations in this transcription factor, we have shown here that they have a decreased hypertrophic response to $\beta$-adrenergic stimulation as shown by a greatly diminished increase in $\mathrm{HW} / \mathrm{BW}$ ratio and by a decrease in cardiac function in response to isoproterenol treatment. Middle-aged MITF-mutated mice have decreased cardiac mass and decreased cardiac function. Thus, the above observations indicate that, while MITF-mutated mice do not respond to various stimuli with cardiac hypertrophy, they develop a decreased cardiac function and $\mathrm{CO}$. These mice are also unable to increase BNP expression in response to $\beta$-adrenergic stimulation, unlike their normal littermates.

PAX3 has been previously shown to be an important regulator of MITF in melanocytes. Since PAX3 has been described as playing a significant role in cardiac development (23), we studied its possible involvement in the regulation of MITF transcriptional activity in cardiomyocytes. Our data indicate that, as opposed to its effect on the MITF M promoter, PAX3 does not regulate the MITF H promoter, which is the main isoform expressed in the heart. Surprisingly, the $\beta$ agonist isoproterenol induces the MITF $H$ promoter but not the MITF M promoter. Thus, MITF expression in different cells would seem to be regulated at least partially by different transcription factors. Further investigation is warranted to understand in detail the regulation of MITF in cardiomyocytes.

$\beta$ agonists induce protein kinase A (PKA) activity (reviewed in ref. 24), and PKA has been recently shown to induce MITF expression through both cAMP response element binding protein-mediated (CREB-mediated) and non-CREB-mediated mechanisms in melanocytes; this activation is critical for melanogenesis (25). Its importance to MITF signaling in cardiomyocytes remains to be determined. However, computer analysis of MITF H promoter reveals several CREB-binding sites, suggesting a similar mechanism.

It is known that during isoproterenol-induced cardiac hypertrophy, the level of BNP increases dramatically (26). However, in MITFmutated mice, this response is significantly blunted. It was recently shown that BNP is an important regulator of cardiac hypertrophy $(26,27)$. Npr1/- mice, which lack the natriuretic peptide receptor NPR-A, have cardiac hypertrophy, and BNP levels were directly proportional to the increase in heart mass (28). Furthermore, these mice exhibited cardiac dilatation and sudden death in some of the animals. The mechanisms responsible for the regulation of BNP transcription are still not understood. We have shown here, using siRNA technol-

\section{Table 4}

Morphometric measurement of 15-month-old MITF-mutated mice $(c e / c e)$ and their normal littermates (sp/sp)

\begin{tabular}{|c|c|c|c|c|c|c|c|c|}
\hline & $\begin{array}{l}\text { BW } \\
(\mathrm{g})\end{array}$ & $\begin{array}{c}\text { HW } \\
(\mathrm{mg})\end{array}$ & $\begin{array}{c}\mathrm{TL} \\
(\mathrm{mm})\end{array}$ & $\begin{array}{c}\text { HW/BW } \\
(\mathrm{mg} / \mathrm{g})\end{array}$ & $\begin{array}{l}\mathrm{HW} / \mathrm{TL} \\
(\mathrm{mg} / \mathrm{g})\end{array}$ & $\begin{array}{l}\text { BV/BW } \\
\text { (mg/g) }\end{array}$ & $\begin{array}{l}\text { LV/BW } \\
\text { (mg/g) }\end{array}$ & $\begin{array}{l}\mathrm{RV} / \mathrm{BW} \\
(\mathrm{mg} / \mathrm{g})\end{array}$ \\
\hline$s p / s p(n=8)$ & $30.6 \pm 0.8$ & $166.1 \pm 5.4$ & $18.1 \pm 0.2$ & $5.44 \pm 0.18$ & $9.21 \pm 0.36$ & $4.21 \pm 0.11$ & $2.36 \pm 0.08$ & $1.93 \pm 0.09$ \\
\hline ce/ce $(n=6)$ & $\begin{array}{c}29.6 \pm 1.2 \\
\text { NS }\end{array}$ & $\begin{array}{c}124.8 \pm 7.6 \\
<0.005\end{array}$ & $\begin{array}{c}17.6 \pm 0.1 \\
<0.05\end{array}$ & $\begin{array}{c}4.22 \pm 0.21 \\
<0.001\end{array}$ & $\begin{array}{c}7.08 \pm 0.41 \\
<0.005\end{array}$ & $\begin{array}{c}3.31 \pm 0.13 \\
<0.001\end{array}$ & $\begin{array}{c}1.99 \pm 0.08 \\
<0.01\end{array}$ & $\begin{array}{c}1.24 \pm 0.06 \\
<0.0005\end{array}$ \\
\hline
\end{tabular}

MITF-mutated mice have decreased heart and chamber weights. TL, tibial length; BV, both ventricles. Results are expressed as mean \pm SEM. 


\section{Table 5}

Echocardiographic measurement of 15-month-old MITF-mutated mice (ce/ce) and their normal littermates $(s p / s p)$

\begin{tabular}{|c|c|c|c|c|c|c|c|c|c|}
\hline & $\begin{array}{l}\text { LVEDD } \\
(\mathrm{mm})\end{array}$ & $\begin{array}{l}\text { LVESD } \\
(\mathrm{mm})\end{array}$ & $\begin{array}{l}\text { IVSd } \\
(\mathrm{mm})\end{array}$ & $\begin{array}{l}\text { IVSs } \\
(\mathrm{mm})\end{array}$ & $\begin{array}{l}\text { LPWd } \\
(\mathrm{mm})\end{array}$ & $\begin{array}{l}\text { SF } \\
(\%)\end{array}$ & $\underset{(\mathrm{bpm})}{\mathrm{HR}}$ & $\begin{array}{c}\text { CO } \\
(\mathrm{ml} / \mathrm{min})\end{array}$ & $\begin{array}{c}\text { Cardiac index } \\
(\mathrm{ml} / \mathrm{min} / \mathrm{g})\end{array}$ \\
\hline$s p / s p(n=8)$ & $3.34 \pm 0.09$ & $1.87 \pm 0.13$ & $0.41 \pm 0.01$ & $0.63 \pm 0.03$ & $0.45 \pm 0.03$ & $43.9 \pm 3.0$ & $473 \pm 10$ & $75.9 \pm 10.0$ & $2.43 \pm 0.30$ \\
\hline ce/ce $(n=6)$ & $\begin{array}{c}3.61 \pm 0.19 \\
\text { NS }\end{array}$ & $\begin{array}{l}2.43 \pm 0.17 \\
\quad<0.05\end{array}$ & $\begin{array}{c}0.38 \pm 0.01 \\
\text { NS }\end{array}$ & $\begin{array}{c}0.52 \pm 0.02 \\
<0.01\end{array}$ & $\begin{array}{l}0.42 \pm 0.02 \\
\text { NS }\end{array}$ & $\begin{array}{c}32.8 \pm 2.1 \\
<0.01\end{array}$ & $\begin{array}{c}433 \pm 27 \\
N S\end{array}$ & $\begin{array}{c}42.7 \pm 3.7 \\
<0.01\end{array}$ & $\begin{array}{c}1.46 \pm 0.14 \\
<0.01\end{array}$ \\
\hline
\end{tabular}

Decreased SF and decreased CO were seen in ce/ce mice. CO was calculated from the velocity-time integral and aortic root cross-sectional area. IVSs, interventricular septum systolic diameter. Results are expressed as mean \pm SEM.

ogy and by overexpression, that MITF expression is important for $\mathrm{BNP}$ promoter activity. Whether MITF is one of the direct regulators of BNP expression has yet to be investigated. However, several MITFbinding sites can be found in the BNP promoter region.

p-ERK was not induced in MITF-mutated mice, in contrast with normal mice, and therefore, this hypertrophic pathway seems to be impaired, potentially resulting in increased cellular load as noted by increased p-Akt and ANP in the MITF-mutated mice and by the decrease in cardiac function (Figure 6). Furthermore, our results demonstrate a novel role for MITF in the phosphorylation of ERK but not in its expression. TFE3, which is closely related to MITF, has been recently shown to increase ERK phosphorylation but not its expression in hepatocytes (29), indicating that transcription factors of the MiT family might be involved in a feedback loop on MAPKs. Interestingly, MITF binds with high affinity both phosphorylated and unphosphorylated ERK1 and ERK2 (30) and therefore might affect the ERK activation cascade.

MITF was previously shown to regulate cathepsin K expression in osteoclasts (31). There is redundancy in function between MITF and TFE 3 in the regulation of cathepsin $\mathrm{K}$, and only dominantnegative MITF mutations result in impaired expression (32). Since both $\mathrm{tg} / \mathrm{tg}$ and $\mathrm{ce} / \mathrm{ce}$ mutations are recessive mutations, we do not expect that cathepsin $\mathrm{K}$ would be affected. Although cathepsin $\mathrm{K}$ is crucial for bone remodeling (33), there is currently no evidence that cathepsin $\mathrm{K}$ mutations cause cardiac pathology, and cathepsin $\mathrm{K}$ is mainly expressed in osteoclasts. Furthermore, dilated cardiomyopathy was described in cathepsin L-deficient mice (34) while the phenotype we observed for MITFmutated mice is characterized mainly in decreased cardiac mass. Therefore, we do not believe that cathepsin $\mathrm{K}$ is related to the cardiac pathology observed by us.

MITF was traditionally described as a transcription factor that is specifically expressed in mast cells, melanocytes, osteoclasts, and retinal pigmented epithelium. In these cells, MITF regulates the transcription of cell-specific genes. This transcription factor has been recently linked to the control of cell-cycle arrest by interaction with Rb1 and p21Cip1 (35) and the regulation of cyclin-dependent kinase 2 (CDK2) (36). Although cardiomyocytes undergo terminal differentia-

Figure 4 mutated (ce/ce) mice. tion soon after birth, irreversibly withdrawing from the cell cycle, growth stimulation does induce cell hypertrophy. Such growth stimulation is also responsible for the upregulation of G1 cyclins and CDK activity in proliferating cells (37), including CDK2 (38). Thus, it would seem that MITF plays a much broader role than traditionally described both in function and in tissue specificity. A role in hypertrophy was recently described for TFE3, which is closely related to MITF. Overexpression of TFE3 caused hypertrophy of hepatocytes and hepatomegaly (29). The current work suggests a new role for MITF in the regulation of cardiac hypertrophy.

One possible explanation for the cardiac hypotrophy of the MITF-mutated mice could be a defect in the growth hormoneIGF (GH-IGF) axis. Despite extensive research on the GH-IGF axis, neither MITF nor any bHLH-Zip transcription factors were ever implicated in the regulation of this axis. Furthermore, while both GH receptor- and IGF-I-null mice have decreased BW (39), neither $\mathrm{tg} / \mathrm{tg}$ nor $\mathrm{ce} / \mathrm{ce}$ mutated mice have decreased BW. GH receptor-null mice do not exhibit cardiac hypotrophy (39). Thus, the GH-IGF axis does not seem to be related to our findings.

Further investigation is needed in order to fully decipher the role played by MITF in the physiology of the heart, its regula-
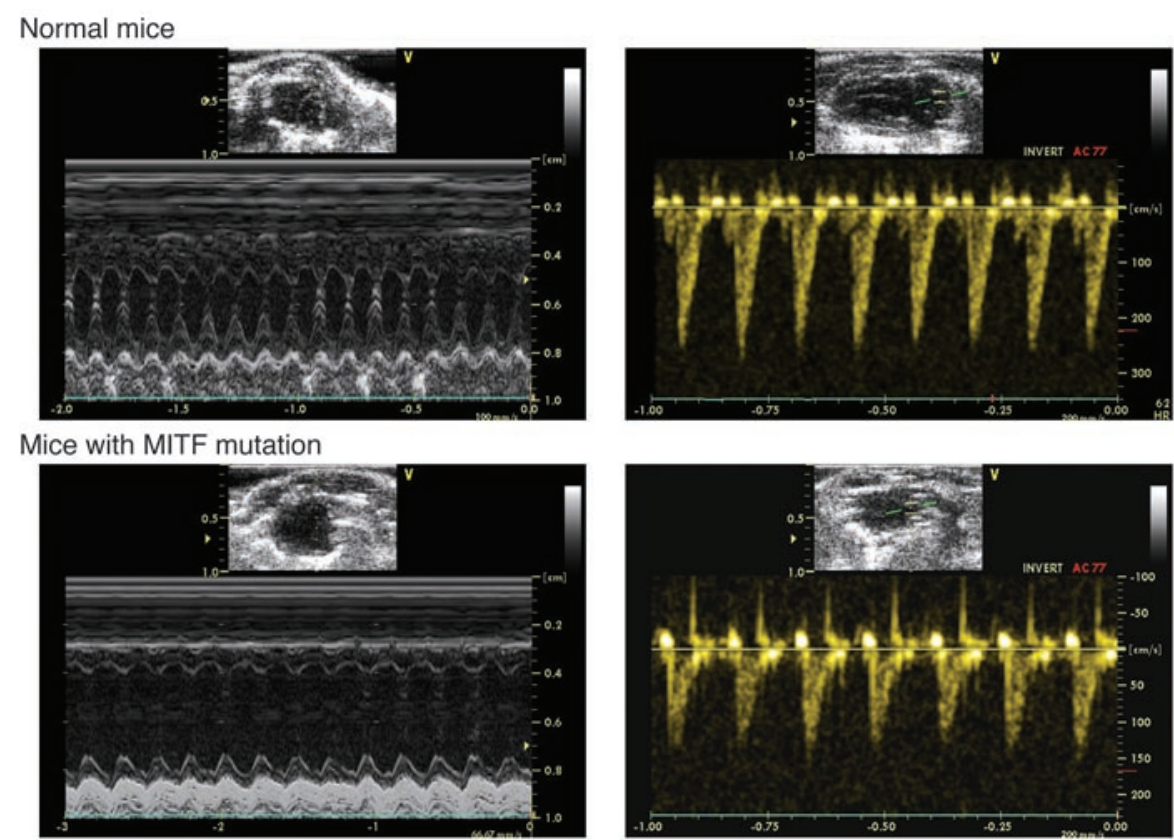

M-mode (left) and Doppler echocardiograms (right) of 15-month-old normal ( $s p / s p)$ and MITF- 
A

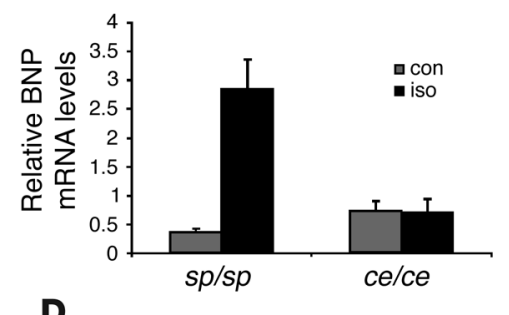

D

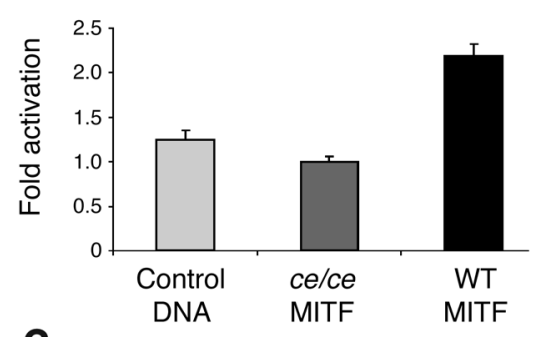

G

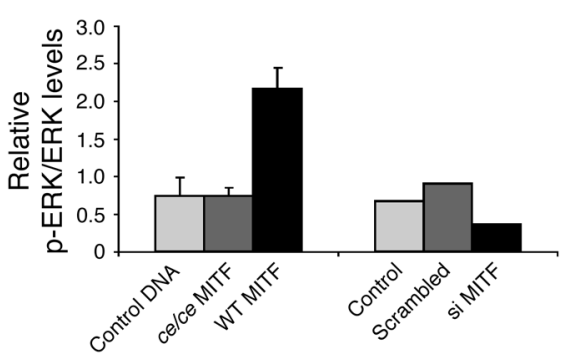

B

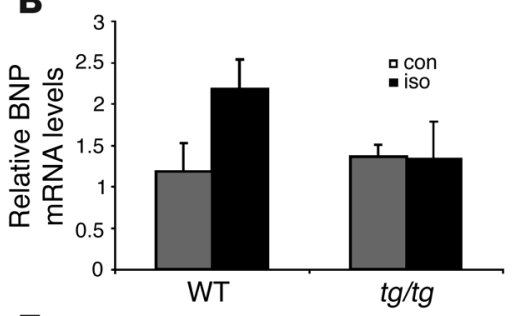

E

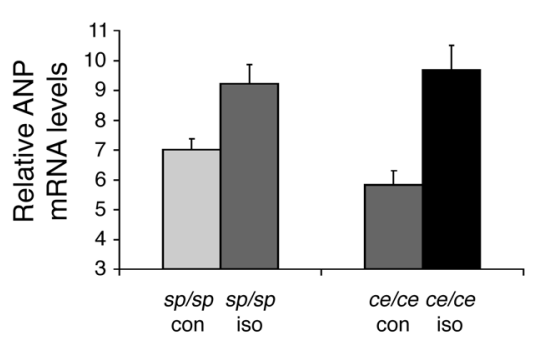

H

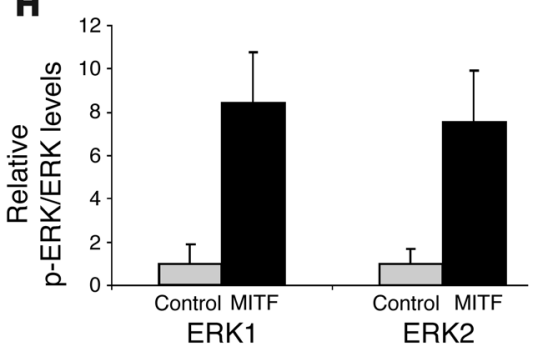

C
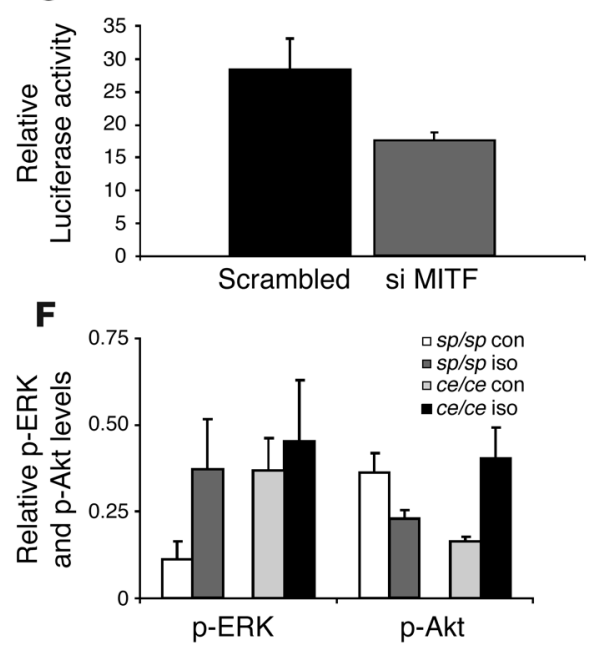

Figure 5

Expression and phosphorylation of cardiac hypertrophy markers. (A and B) Real-time PCR quantification of BNP mRNA in hearts of ce/ce (A) and $\mathrm{tg} / \mathrm{tg}$ (B) MITF-mutated mice and their normal littermates ( $s p / s p$ and WT). Mice were administered either saline or isoproterenol. (C) H9C2 cells were transduced with lentiviral vector expressing either scrambled RNA or MITF-specific siRNA (siMITF). After 24 hours, cells were transfected with BNP reporter construct. siRNA directed against MITF caused significant reduction in BNP promoter activity. (D) WT MITF H or ce/ce MITF expression vectors were cotransfected into H9C2 cardiomyocytes with pGL-BNP promoter reporter for 48 hours. Results are expressed as fold activation relative to ce/ce MITF. (E) Real-time PCR quantification of ANP expression levels in hearts of ce/ce MITF-mutated mice and their normal littermates (sp/sp). (F) ERK and Akt phosphorylation was determined in ce/ce mutated mice and their normal littermates 16 hours after the last isoproterenol injection by Western blot analysis. Densitometry results are expressed relative to $\beta$-actin. (G) H9C2 cells were transfected with either control vector, ce/ce MITF, or WT MITF expression vectors for 48 hours (left). Western blot analysis of $p$-ERK and ERK. Densitometry results are expressed as $p$-ERK/ERK ratio. Primary neonatal cardiomyocytes were transduced with either scrambled or MITF-specific siRNA (siMITF) or untransfected (control) (right). (H) p-ERK1/ERK1 and p-ERK2/ERK2 ratios of the same experiment. Results in all panels represent mean \pm SEM.

tion, and its participation in different signal transduction pathways in cardiac hypertrophy.

\section{Methods}

Cell culture. NIH 3T3 and H9C2 cells were cultured in growth medium as previously described (21). Myocardial cells from ventricle fragments of hearts of 1-day-old Sprague-Dawley rats were isolated by serial trypsinization as previously described (40). Cells were suspended in F-10 medium (Biological Industries) containing $10 \%$ heat-inactivated fetal calf serum and $10 \%$ horse serum (Biological Industries) and penicillin-streptomycin antibiotic solution. This medium was also used as the standard culture medium in the experiments. The cell suspensions were enriched with myocytes by preplating on tissue culture dishes for 30 minutes to allow attachment of fibroblasts. The cells were plated on 60-mm Petri dishes at a density of $10^{6}$ cells $/ \mathrm{ml}$.

Mice. All mice lines were held and propagated in a specific pathogen-free environment. MITF $s p / s p$ and MITF $F^{s p / c e}$ were kindly provided by L. Lamoreux (College of Veterinary Medicine, Texas A\&M University, College Station, Texas, USA) and bred to produce $s p / s p$ and $c e / c e$ mice for experiments. The MITF encoded by the mutated mouse allele (ce/ce) lack the zip domain of MITF because of a stop codon between the HLH and zip domains while their normal littermates $(s p / s p)$ express the full-length protein, except the 6 amino acids of exon $6 a$ (11). $V G A-9^{\text {tg/ }}$ - mice were kindly provided by $\mathrm{H}$. Arnheiter (NIH, Bethesda, Maryland, USA). Mice carrying the $\mathrm{tg} / \mathrm{tg}$ mutation have an insertion of approximately 50 copies of a transgene integrated inside the MITF promoter and are unable to express MITF (Figure 1B). Normal littermates of $\mathrm{tg} / \mathrm{tg}$ mice were determined by genomic DNA extraction from tails and subsequent PCR analysis. Normal littermates of $c e / c e$ mice ( $s p / s p)$ were distinguished by coat color.

Six-week-old $s p / s p$ and $c e / c e$ mutated mice were administered either $5 \mathrm{mg} / \mathrm{kg}$ isoproterenol (Sigma-Aldrich) or saline subcutaneously for 7 days for the induction of cardiac hypertrophy. Animals were killed and HW/BW ratios were calculated and expressed as milligrams HW per gram BW. All experiments were performed in compliance with the Israeli Prevention of Cruelty to Animals Law and were approved by the Hebrew University Animal Care and Use Committee. 

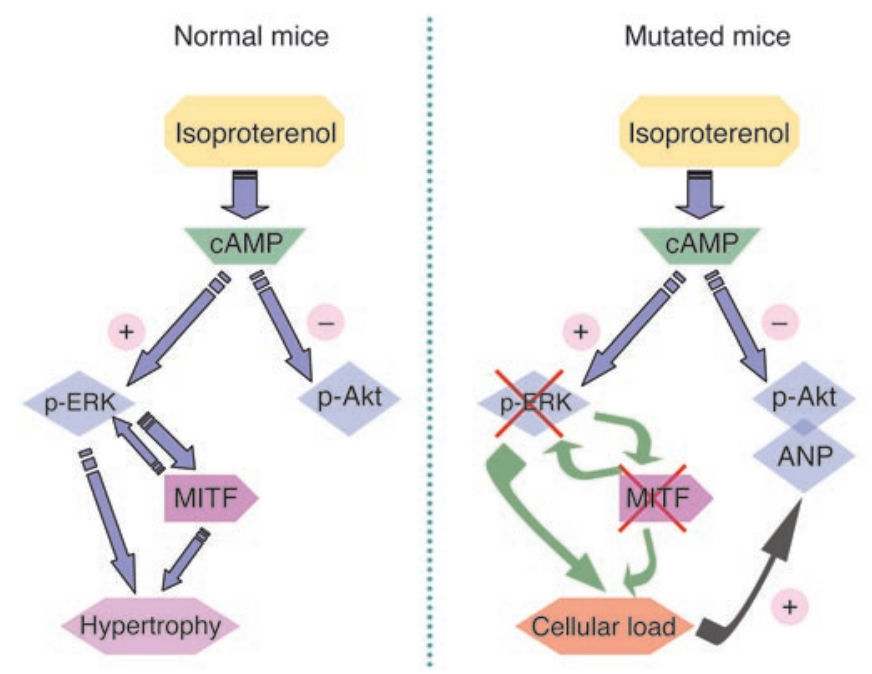

Figure 6

Proposed model for the general molecular mechanism of MITF in cardiac hypertrophy. Following isoproterenol activation, ERK and MITF are activated through cAMP. However, in MITF-mutated mice, both ERK and MITF are not activated while activated Akt and ANP are increased, indicating a cellular load response.

Antibodies. Anti-mouse MITF antibody directed against the $\mathrm{N}$ terminus of MITF (Exalpha Biologicals) and anti-mouse $\beta$-actin antibody (SigmaAldrich), anti-mouse p-ERK and p-Akt (Santa Cruz Biotechnology Inc.), and anti-rabbit ERK (Upstate USA Inc.) were used for Western blots and immunohistochemical staining.

Histology and immunohistochemistry. Formalin-fixed, paraffin-embedded tissue samples were cut into 5 - $\mu \mathrm{m}$ sections, deparaffinized in xylene, and rehydrated through a series of decreasing concentrations of ethanol. Sections were stained with $\mathrm{H} \& \mathrm{E}$ or with the indicated antibodies using the EnVision+ system (Dako) according to the manufacturer's instructions.

To evaluate the mean diameter of LV cardiomyocytes, the shortest diameter of each cardiomyocyte was measured only in nucleated transverse sections stained with $\mathrm{H} \& \mathrm{E}$. At least 30 cardiomyocytes in each $\mathrm{LV}$ were measured using an ocular micrometer disc with a linear scale at a magnification of $\times 400$, and the average cardiomyocyte diameter of each specimen was calculated as previously described (41). Four hearts were measured in each group.

PCR amplification. Total RNA was prepared from hearts of mutant and WT control mice using TRI Reagent (Sigma-Aldrich). For PCR analysis, RNA was reverse transcribed using Expand Reverse Transcriptase (Roche Applied Science). Primers were used to amplify the region between alternative exon 1 and the constant exon 5 of MITF. cDNA from hearts of $c e / c e$ and $t g / t g$ MITF-mutated mice and their normal littermates was used as a template. The resulting PCR products were electrophoresed on agarose gels. The primers used for MITF amplification were as follows: exon 1a, 5'-AAGTCGGGGAGGAGTTTCAT-3'; exon 1e, 5'-TCACAGAGGTTAGTAGGTGGATGGG-3'; exon 1h, 5'-GGCGCTTAGATTTGAGATGC-3'; exon 1m, 5'-GAGGACTAAGTGGTCTGCGG-3'; and exon 5, 5'-GGACAGGAGTTGCTGATGGT-3'.

Real-time quantitative PCR. Candidate MITF responsive genes were measured using real-time quantitative PCR. Total RNA was extracted from hearts of WT, $c e / c e$, and $\mathrm{tg} / \mathrm{tg}$ mice. mRNA levels of various genes were quantified by SYBR Green incorporation (SYBR Green PCR Master Mix; Applied Biosystems) on ABI Prism 7000 Sequence Detection System (Applied Biosystems) and were normalized to $\beta$-actin housekeeping genes.
The primers used for gene amplification for real-time PCR were as follows: $\beta$-actin sense, $5^{\prime}$-CCTGATCCACATCTGCTGGAA- 3 '; $\beta$-actin antisense, $5^{\prime}$-ATTGCCGACAGGATGCAGAA-3'; BNP sense, 5' -CACCGCTGGGAGGTCACT-3'; BNP antisense, $5^{\prime}$-GTGAGGCCTTGGTCCTTCAA-3'; ANP sense, 5'-TTCTTCCTCGTCTTGGCCTTT-3'; and ANP antisense, 5'GACCTCATCTTCTACCGGCATCT-3'.

Plasmid construction. Plasmid pcDNA3.1- vector containing WT MITF was kindly provided by D. Fisher (Dana-Farber Cancer Institute, Boston, Massachusetts, USA). MITF $\mathrm{H}$ isoform was amplified by PCR and ligated into pcDNA using HindIII and EcoRI (New England Biolabs Inc.).

MITF heart-promoter fragments were enhanced using PCR of genomic mouse DNA and were ligated into plasmid pSP72 vector (Promega) using NotI and EcoRI. BNP promoter was enhanced using PCR of genomic mouse DNA from -1421 to +18 and was cloned into pGL3 basic vector (Promega) using KpnI and HindIII.

$R N A$ interference assay. The following primer was designed for inhibition of MITF expression: 5'-CAGCAGCGAGCTAAGGACC-3' (GenBank accession numberXM_232215). It was cloned under the control of the polymerase-III H1RNA promoter, as described previously (42). The cassette of the H1-RNA promoter together with the MITF primer was further cloned in modified HIV-1based SIN18 vector. As control, a scrambled 19-mer H1-RNA promoter construct cloned into the SIN18 vector was used. All the constructs were verified by sequencing. Viruses were produced by transient cotransfection of 3 plasmids into $293 \mathrm{~T}$ cells and concentrated by ultracentrifugation as described earlier. For transduction, H9C2 cells or primary rat neonatal cardiomyocytes were incubated directly with the viral particles in the presence of $5 \mu \mathrm{g} / \mathrm{ml}$ Polybrene (Sigma-Aldrich) at $37^{\circ} \mathrm{C}$ for 2 hours, and then complete medium was added.

Transient cotransfection and luciferase assay. H9C2 cardiomyocytes $\left(2 \times 10^{5}\right)$ were transfected by TransFast Reagent (Promega) with $0.1 \mu \mathrm{g}$ MITF promoter fragments-pSPLuc reporter. Cells were incubated in 24-well plates for 48 hours, then lysed and assayed for luciferase activity. The luciferase activity was normalized to the total protein concentration. MITF M promoter-reporter vector was kindly provided by M. Revel (Weizmann Institute of Science, Rehovot, Israel). NIH 3T3 cells were cotransfected with $0.1 \mu \mathrm{g}$ of either MITF M or MITF H promoter-reporter constructs and Pax3 expression vector, kindly provided by P. Gruss (Max-Planck Institute, Göttingen, Germany). H9C2 cells were transfected with MITF H and M promoter construct and 48 hours later were activated by addition of $10 \mu \mathrm{M}$ isoproterenol to serum-free medium for 6 hours.

Echocardiography. Echocardiograms of MITF-mutated mice and normal littermates were carried out on mice anesthetized with IP administration of ketamine and diazepam according to BW after 7 days of isoproterenol or saline administration. Echo imaging was performed using a GE Vivid 7 platform equipped with a $15 \mathrm{MHz}$ linear epiaortic transducer (GE Healthcare). Measurements were performed in triplicate using the leading edge convention for myocardial borders, as defined by the American Society of Echocardiography (43). The following parameters were measured: LVEDD; LVESD; anterior wall thickness in diastole and systole (AWTd, AWTs); posterior wall thickness in diastole and systole (PWTd, PWTs); and HR. SF was calculated as follows: SF $(\%)=($ LVEDD-LVESD)/LVEDD. Peak HR was assessed by repeated measurements of HR in the first 5 minutes following i.p. administration of isoproterenol $(3 \mathrm{mg} / \mathrm{kg})$. After aortic flow velocity, velocity-time integral (VTI), and aortic root diameter (AoD) were obtained, CO was calculated from the following equation: $\mathrm{CO}=\pi(\mathrm{AoD})^{2} / 4 \times \mathrm{VTI} \times \mathrm{HR}$.

Statistics. Statistical analysis was conducted using Microsoft Excel 2003 software with the Analysis ToolPak and NCSS 2004. Comparisons between mutant mice and their normal littermates were carried out by 2-tailed Student's $t$ test. Additionally, the role of the genotype (mutant and normal littermates) and saline or isoproterenol treatment was evaluated by 2-way ANOVA with repli- 
cation, followed by the Tukey's procedure when appropriate. Null hypothesis was rejected at the $P<0.05$ level. Data are reported as mean \pm SEM.

\section{Acknowledgments}

This work was supported by the United States Binational Science Foundation (96-111 to E. Razin), the Israeli Academy of Science (E. Razin), the German-Israel Foundation for Scientific Research and Development (grant I-726-10.2 to E. Razin), and in part by the Dean's Fund of the Faculty of Medicine of the Hebrew University.
Received for publication December 12, 2005, and accepted in revised form August 8, 2006.

Address correspondence to: Ehud Razin, Department of Biochemistry, Hebrew University Medical School, POB 12272, Jerusalem 91120, Israel. Phone: 972-2-675-8288; Fax: 972-2-675-8986; E-mail: ehudr@cc.huji.ac.il.

\section{Sagi Tshori and Dan Gilon contributed equally to this work.}

1. Van Bilsen, M., and Chien, K.R. 1993. Growth and hypertrophy of the heart: towards an understanding of cardiac specific and inducible gene expression. Cardiovasc. Res. 27:1140-1149.

2. Saadane, N., Alpert, L., and Chalifour, L.E. 1999. Expression of immediate early genes, GATA-4, and Nkx-2.5 in adrenergic-induced cardiac hypertrophy and during regression in adult mice. Br.J. Pharmacol. 127:1165-1176.

3. Akazawa, H., and Komuro, I. 2003. Roles of cardiac transcription factors in cardiac hypertrophy. Circ. Res. 92:1079-1088.

4. Hemesath, T.J., Price, E.R., Takemoto, C., Badalian, T., and Fisher, D.E. 1998. MAP kinase links the transcription factor Microphthalmia to c-Kit signalling in melanocytes. Nature. 391:298-301.

5. Dorsky, R.I., Raible, D.W., and Moon, R.T. 2000. Direct regulation of nacre, a zebrafish MITF homo$\log$ required for pigment cell formation, by the Wnt pathway. Genes Dev. 14:158-162.

6. Takeda, K., et al. 2000. Ser298 of MITF, a mutation site in Waardenburg syndrome type 2 , is a phosphorylation site with functional significance. Hum. Mol. Genet. 9:125-132.

7. Hodgkinson, C.A., et al. 1993. Mutations at the mouse microphthalmia locus are associated with defects in a gene encoding a novel basic-helix-loophelix-zipper protein. Cell. 74:395-404.

8. Hughes, M.J., Lingrel, J.B., Krakowsky, J.M., and Anderson, K.P. 1993. A helix-loop-helix transcription factor-like gene is located at the mi locus. J. Biol. Chem. 268:20687-20690.

9. Moore, K.J. 1995. Insight into the microphthalmia gene. Trends Genet. 11:442-450.

10. Tassabehji, M., Newton, V.E., and Read, A.P. 1994. Waardenburg syndrome type 2 caused by mutations in the human microphthalmia (MITF) gene. Nat. Genet. 8:251-255.

11. Steingrimsson, E., et al. 1994. Molecular basis of mouse microphthalmia (mi) mutations helps explain their developmental and phenotypic consequences. Nat. Genet. 8:256-263.

12. Hemesath, T.J., et al. 1994. Microphthalmia, a critical factor in melanocyte development, defines a discrete transcription factor family. Genes Dev. 8:2770-2780.

13. Ito, A., et al. 1999. Inhibitory effect of the transcription factor encoded by the mi mutant allele in cultured mast cells of mice. Blood. 93:1189-1196.

14. Bentley, N.J., Eisen, T., and Goding, C.R. 1994. Melanocyte-specific expression of the human tyrosinase promoter: activation by the microphthalmia gene product and role of the initiator. Mol. Cell. Biol. 14:7996-8006.

15. Isozaki, K., et al. 1994. Cell type-specific deficiency of c-kit gene expression in mutant mice of $\mathrm{mi} / \mathrm{mi}$ genotype. Am. J. Pathol. 145:827-836.
16. Ito, A., et al. 1998. Systematic method to obtain novel genes that are regulated by mi transcription factor: impaired expression of granzyme B and tryptophan hydroxylase in $\mathrm{mi} / \mathrm{mi}$ cultured mast cells. Blood. 91:3210-3221.

17. Morii, E., et al. 1996. Regulation of mouse mast cell protease 6 gene expression by transcription factor encoded by the $m i$ locus. Blood. 88:2488-2494.

18. Nechushtan, H., Zhang, Z., and Razin, E. 1997. Microphthalmia (mi) in murine mast cells: regulation of its stimuli-mediated expression on the translational level. Blood. 89:2999-3008.

19. Sato, M., et al. 1999. Microphthalmia-associated transcription factor interacts with PU.1 and c-Fos: determination of their subcellular localization. Biochem. Biophys. Res. Commun. 254:384-387.

20. Razin, E., et al. 1999. Suppression of microphthalmia transcriptional activity by its association with protein kinase C-interacting protein 1 in mast cells. J. Biol. Chem. 274:34272-34276.

21. Levy, C., Nechushtan, H., and Razin, E. 2002. A new role for the STAT3 inhibitor, PIAS3: a repressor of microphthalmia transcription factor. J. Biol. Chem. 277:1962-1966.

22. Weilbaecher, K.N., et al. 1998. Age-resolving osteopetrosis: a rat model implicating microphthalmia and the related transcription factor TFE3. J. Exp. Med. 187:775-785.

23. Schafer, K., Neuhaus, P., Kruse, J., and Braun, T. 2003. The homeobox gene Lbx1 specifies a subpopulation of cardiac neural crest necessary for normal heart development. Circ. Res. 92:73-80.

24. Salathe, M. 2002. Effects of beta-agonists on airway epithelial cells. J. Allergy Clin. Immunol. 110:S275-S281.

25. Ji, M., and Andrisani, O.M. 2005. High-level activation of cyclic AMP signaling attenuates bone morphogenetic protein 2 -induced sympathoadrenal lineage development and promotes melanogenesis in neural crest cultures. Mol. Cell. Biol. 25:5134-5145.

26. Gardner, D.G. 2003. Natriuretic peptides: markers or modulators of cardiac hypertrophy? Trends Endocrinol. Metab. 14:411-416.

27. Tamura, N., et al. 2000. Cardiac fibrosis in mice lacking brain natriuretic peptide. Proc. Natl. Acad. Sci. U. S. A. 97:4239-4244.

28. Ellmers, L.J., et al. 2002. Ventricular expression of natriuretic peptides in $\mathrm{Npr} 1(-/-)$ mice with cardiac hypertrophy and fibrosis. Am. J. Physiol. Heart Circ. Physiol. 283:H707-H714.

29. Nakagawa, Y., et al. 2006. TFE3 transcriptionally activates hepatic IRS-2, participates in insulin signaling and ameliorates diabetes. Nat. Med. 12:107-113.

30. Molina, D.M., Grewal, S., and Bardwell, L. 2005. Characterization of an ERK-binding domain in microphthalmia-associated transcription factor and differential inhibition of ERK2-medi- ated substrate phosphorylation. J. Biol. Chem. 280:42051-42060.

31. Motyckova, G., et al. 2001. Linking osteopetrosis and pycnodysostosis: regulation of cathepsin $\mathrm{K}$ expression by the microphthalmia transcription factor family. Proc. Natl. Acad. Sci. U. S. A. 98:5798-5803.

32. Steingrimsson, E., et al. 2002. Mitf and Tfe3, two members of the Mitf-Tfe family of bHLH-Zip transcription factors, have important but functionally redundant roles in osteoclast development. Proc. Natl. Acad. Sci. U. S. A. 99:4477-4482.

33. Troen, B.R. 2004. The role of cathepsin $\mathrm{K}$ in normal bone resorption. Drug News Perspect. 17:19-28.

34. Stypmann, J., et al. 2002. Dilated cardiomyopathy in mice deficient for the lysosomal cysteine peptidase cathepsin L. Proc. Natl. Acad. Sci. U. S. A. 99:6234-6239.

35. Carreira, S., et al. 2005. Mitf cooperates with Rb1 and activates p21Cip1 expression to regulate cell cycle progression. Nature. 433:764-769.

36. Du, J., et al. 2004. Critical role of CDK2 for melanoma growth linked to its melanocyte-specific transcriptional regulation by MITF. Cancer Cell. 6:565-576.

37. Tamamori, M., et al. 1998. Essential roles for G1 cyclin-dependent kinase activity in development of cardiomyocyte hypertrophy. Am. J. Physiol. 275:H2036-H2040.

38. Sadoshima, J., Aoki, H., and Izumo, S. 1997. Angiotensin II and serum differentially regulate expression of cyclins, activity of cyclin-dependent kinases, and phosphorylation of retinoblastoma gene product in neonatal cardiac myocytes. Circ. Res. 80:228-241.

39. Lupu, F., Terwilliger, J.D., Lee, K., Segre, G.V., and Efstratiadis, A. 2001. Roles of growth hormone and insulin-like growth factor 1 in mouse postnatal growth. Dev. Biol. 229:141-162.

40. Hallaq, H., Hasin, Y., Fixler, R., and Eilam, Y. 1989. Effect of ouabain on the concentration of free cytosolic $\mathrm{Ca}^{++}$and on contractility in cultured rat cardiac myocytes. J. Pharmacol. Exp. Ther. 248:716-721.

41. Mori, T., et al. 2004. Volume overload results in exaggerated cardiac hypertrophy in the atrial natriuretic peptide knockout mouse. Cardiovasc. Res. 61:771-779.

42. Gropp, M., et al. 2003. Stable genetic modification of human embryonic stem cells by lentiviral vectors. Mol. Ther. 7:281-287.

43. Schiller, N.B., et al. 1989. Recommendations for quantitation of the left ventricle by two-dimensional echocardiography. American Society of Echocardiography Committee on Standards, Subcommittee on Quantitation of Two-Dimensional Echocardiograms. J. Am. Soc. Echocardiogr. 2:358-367. 